\title{
A Versatile Assay for the Identification of RNA Silencing Suppressors Based on Complementation of Viral Movement
}

\author{
Jason G. Powers, ${ }^{1}$ Tim L. Sit, ${ }^{2}$ Feng Qu, ${ }^{3}$ T. Jack Morris, ${ }^{3}$ Kook-Hyung Kim, ${ }^{4}$ and Steven A. Lommel \\ ${ }^{1}$ Department of Genetics, North Carolina State University, Box 7614, Raleigh, NC 27695-7614, U.S.A.; ${ }^{2}$ Department of Plant \\ Pathology, North Carolina State University, Box 7342, Raleigh, NC 27695-7342, U.S.A.; ${ }^{3}$ School of Biological Sciences, \\ University of Nebraska-Lincoln, Lincoln, NE 68588-0666, U.S.A.; ${ }^{4}$ Department of Agricultural Biotechnology, Seoul \\ National University, Seoul 151-921, Korea
}

Submitted 22 January 2008. Accepted 20 March 2008.

\begin{abstract}
The cell-to-cell movement of Turnip crinkle virus (TCV) in Nicotiana benthamiana requires the presence of its coat protein (CP), a known suppressor of RNA silencing. RNA transcripts of a TCV construct containing a reporter gene (green fluorescent protein) (TCV-sGFP) in place of the $\mathrm{CP}$ open reading frame generated foci of three to five cells. TCV CP delivered in trans by Agrobacterium tumefaciens infiltration potentiated movement of TCV-sGFP and increased foci diameter, on average, by a factor of four. Deletion of the TCV movement proteins in TCV-sGFP (construct TCV $\triangle 92$-sGFP) abolished the movement complementation ability of TCV CP. Other known suppressors of RNA silencing from a wide spectrum of viruses also complemented the movement of TCV-sGFP when delivered in trans by Agrobacterium tumefaciens. These include suppressors from nonplant viruses with no known plant movement function, demonstrating that this assay is based solely on RNA silencing suppression. While the TCV-sGFP construct is primarily used as an infectious RNA transcript, it was also subcloned for direct expression from Agrobacterium tumefaciens for simple quantification of suppressor activity based on fluorescence levels in whole leaves. Thus, this system provides the flexibility to assay for suppressor activity in either the cytoplasm or nucleus, depending on the construct employed.
\end{abstract}

Additional keywords: IVIS Lumina, p8, p9, pPZP212, VSR.

The study of RNA silencing (gene expression regulation based on small RNAs) is still in its relative infancy (Chapman and Carrington 2007). Despite this short history, this mechanism has been implicated in the control of endogenous gene expression (Napoli et al. 1990), transposable elements (Tabara et al. 1999), and heterochromatin formation (Volpe et al. 2002) and has been shown to be a powerful host defense mechanism against pathogens (Brigneti et al. 1998). This latter role of host defense has been shown to be especially relevant in plants, invertebrates, and to a lesser extent, fungi (Galiana-Arnoux et al.

Corresponding author: S. A. Lommel; E-mail: steve_lommel@ncsu.edu

* The $\boldsymbol{e}$-Xtra logo stands for "electronic extra" and indicates that Figures 1,3 , and 4 appear in color online.
2006; Segers et al. 2006; Voinnet 2001; Wang et al. 2006). In order to survive in hosts employing RNA silencing, viruses have evolved a counterdefense by encoding proteins that disrupt the RNA silencing pathway, termed viral suppressors of RNA silencing (VSR) (Li and Ding 2006). In plants, this RNA silencing pathway targeting viruses begins with a Dicer-like ribonuclease, primarily DCL4 when targeting RNA viruses (Deleris et al. 2006), which recognizes double-stranded RNAs (dsRNA) and cleaves them into 21- to 24-nt dsRNA duplexes (Bernstein et al. 2001; Blevins et al. 2006). These small duplexes are unwound, and one strand is incorporated into the RNA-induced silencing complex (RISC). RISC containing the RNA strand and a protein known as Argonaute can then target complementary viral RNA for degradation (Baumberger and Baulcombe 2005; Song et al. 2004). The RNA silencing signal can also be amplified by host RNA-dependent RNA polymerases promoting the spread of the signal from cell-to-cell (Himber et al. 2003; Mourrain et al. 2000).

A variety of mechanistically different assays have been developed to identify and characterize VSR $(\mathrm{Qu}$ and Morris 2005). One commonly used assay is based on the coinfiltration of separate Agrobacterium tumefaciens cultures harboring the putative VSR and a reporter gene (typically green fluorescent protein [GFP]) onto Nicotiana benthamiana (Johansen and Carrington 2001). In the absence of a functional VSR, GFP expression from the Ti-plasmid is recognized as exogenous by the host and is silenced within 3 days postinfiltration. If the VSR is operational, the expression level of GFP is stabilized beyond 7 days postinfiltration. Another common assay examines the ability of an expressed putative VSR to reverse silencing of a presilenced transgenic reporter gene in a host plant (Brigneti et al. 1998). Other VSR have been identified using techniques such as grafting (Voinnet et al. 2000), transgenic Arabidopsis thaliana or $N$. benthamiana expressing putative suppressors (Anandalakshmi et al. 1998; Deleris et al. 2006; Kasschau and Carrington 1998), and cell culture (Li et al. 2002; Li et al. 2004). Each assay has its advantages and disadvantages and the ability to detect VSR that act at different steps in the silencing pathway. The coinfiltration assay, for example, is easy and quick; however, it is not highly sensitive and does not identify suppressors affecting systemic silencing (Lu et al. 2004). Meanwhile, grafting can detect VSR affecting systemic silencing but can be time consuming, as can work that involves presilencing of transgenic plants. 
In this report, we describe the development of a new, simple VSR assay based on the biological properties of Turnip crinkle virus (TCV), a positive-sense RNA virus in the Carmovirus genus, Tombusviridae family. The TCV coat protein (CP) has been shown to have at least three biological functions: i) the structural protein for virion formation, ii) as an interactor with the endogenous TIP protein, a transcription factor involved in the defense response (Ren et al. 2000, 2005), and iii) as a VSR $(\mathrm{Qu}$ et al. 2003). Deletion of the CP gene from TCV (TCV $\triangle \mathrm{CP}$ ) has no effect on cell-to-cell movement in $A$. thaliana, but previous reports have indicated that TCV $\triangle \mathrm{CP}$ is incapable of moving cell-to-cell in $N$. benthamiana (Cohen et al. 2000; Hacker et al. 1992; Li et al. 1998). We found that providing the TCV CP in trans via Agrobacterium tumefaciens potentiates TCV-sGFP movement beyond the initially infected cells. Deletion of the TCV movement proteins (MP) abolishes movement complementation by $\mathrm{TCV} \mathrm{CP}$, demonstrating that TCV CP does not have an inherent independent movement function. Previously described VSR from viruses that infect plants, insects, and animals also restore the movement of TCVsGFP. This movement phenotype serves as the basis for this new and simple assay. Mobilizing the TCV-sGFP construct into Agrobacterium tumefaciens provides a second delivery method for the reporter, underscoring the versatility of the system.

\section{RESULTS}

TCV movement is limited to three to five cells in $N$. benthamiana after CP deletion.

It has been previously reported that TCV $\mathrm{CP}$ open reading frame (ORF) deletion mutants move cell-to-cell in A. thaliana but not in N. benthamiana (Cohen et al. 2000; Hacker et al. 1992; $\mathrm{Li}$ et al. 1998). We attempted to confirm these results by replacing the TCV CP ORF with sGFP, resulting in a virus construct termed TCV-sGFP (Fig. 1A). Infectious transcripts from this construct were mechanically inoculated onto $N$. benthamiana plants. Inoculated leaves were observed 3 days postinoculation (dpi) using a fluorescence microscope. TCVsGFP movement was greatly reduced compared with wild-type virus, but a three- to five-cell foci of infection was regularly observed, suggesting compromised movement (Fig. 1C, panel a). This observation was in contrast to a previous study that

A TCV

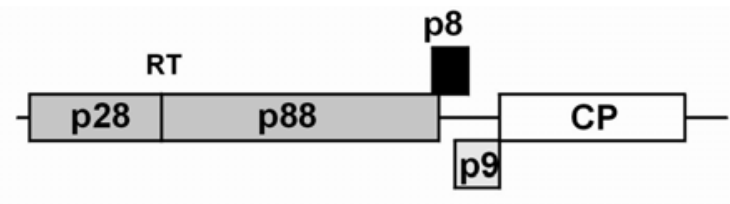

TCV-sGFP

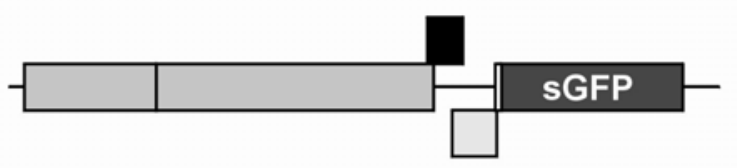

$\operatorname{TCV} \Delta$ 92-sGFP

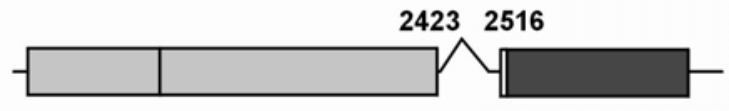

B

PZP-TCV-sGFP

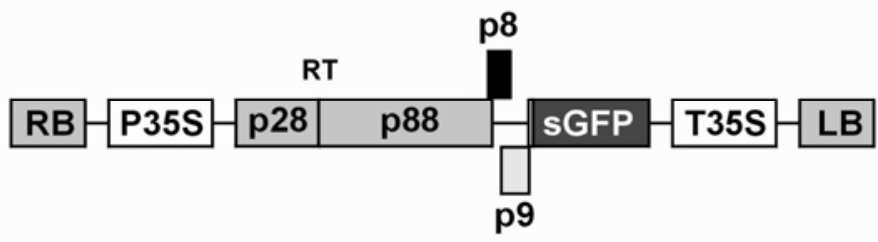

pPZP212 + VSR

RB P35S TE VSR T35S LB

C
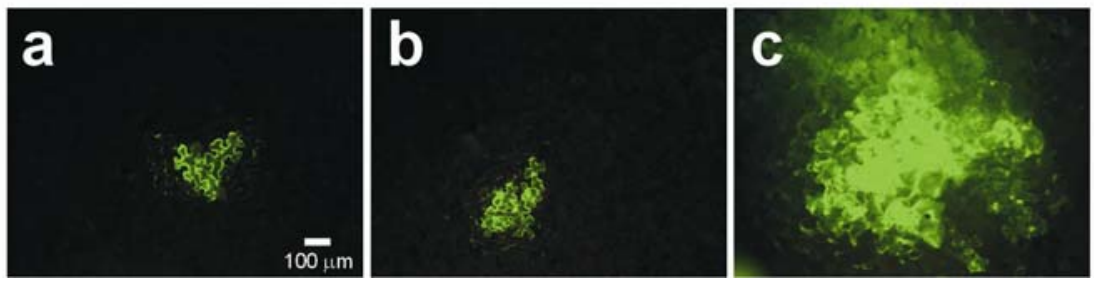

Fig. 1. Schematic of plasmid constructs and response to transcript inoculation on leaves expressing Turnip crinkle virus coat protein (TCV CP). A, TCV infectious transcript constructs (only the transcribed RNA is shown). TCV: wild-type TCV; TCV-sGFP: the CP open reading frame (ORF) was replaced with the construct containing a green fluorescent protein reporter gene ORF. TCV $\triangle 92$-sGFP: movement deficient mutant that contains a deletion from nt 2,423 to 2,516. The $\mathrm{p} 28$ and $\mathrm{p} 88$ ORF code for the replication proteins, with p88 expressed as an amber codon translational readthrough (RT). p8 and p9 encode for the cell-to-cell movement proteins. B, Agrobacterium Ti-plasmid constructs. All constructs are based on the pPZP212 vector. PZP-TCV-sGFP contains the TCV-sGFP construct from (A) under control of the 35S promoter. pPZP212 + VSR (viral suppressors of RNA silencing) shows the expression cassettes (derived from pRTL2) that the candidate VSR were cloned into. RB and LB: right and left borders, respectively; P35S and T35S: 35S promoter and terminator, respectively; TE: Tobacco etch virus translational enhancer. C, Images of infection foci three days postinoculation on Nicotiana benthamiana are presented in panels a to c. a) TCV-sGFP, no preinfiltration; b) TCV-sGFP preinfiltrated with pPZP212; and c) TCV-sGFP preinfiltrated with PZP-TCV CP. 
showed that TCV-GFP was restricted to initially inoculated single cells (Cohen et al. 2000). Repeat observations at 5 dpi failed to detect an increase in the size of the infection foci. In this study, we used an enhanced sGFP that had been optimized for very high levels of fluorescence in plants (Chiu et al.
1996). We believe that the conflicting results are due to the fact that the GFP originally used was less sensitive and, therefore, did not detect virus infection beyond the initially infected cell. Indeed a direct comparison between TCV-sGFP and a TCV-cycle 3 GFP construct (TCV-mGC3) showed that TCV-

\section{A TCV-sGFP Complementation Assay}

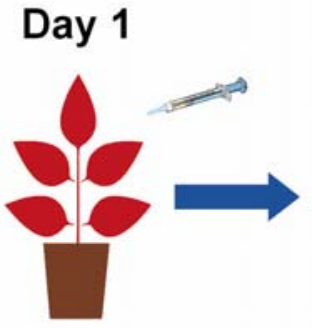

Infiltrate leaves with $A$. tumefaciens containing potential VSR
Day 2

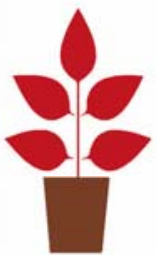

Mechanically inoculate same leaves with infectious TCVsGFP transcripts
Day 5

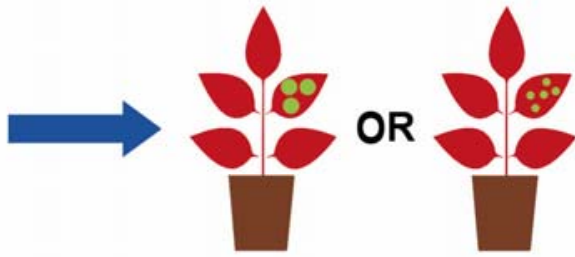

View leaves with UV microscope, examining for foci complementation

\section{B PZP-TCV-sGFP Co-infiltration Assay}

\section{Day 1}

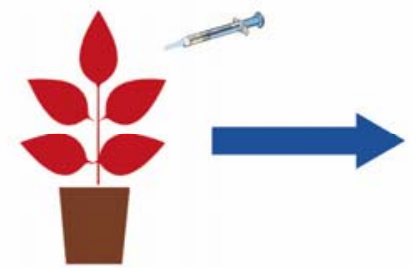

\section{Infiltrate leaves with a mixture of $A$. tumefaciens cultures containing various PZP-VSR constructs and PZP-TCV-sGFP}

Day 5

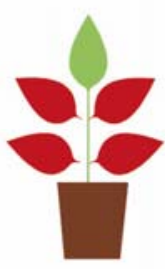

OR

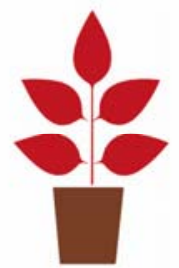

\section{Examine leaves under UV light for increased sGFP expression}

Fig. 2. Turnip crinkle virus construct containing a green fluorescent protein reporter gene (TCV-sGFP) complementation assay and coinfiltration assay. A, A workflow schematic of the TCV-sGFP complementation assay. B, A workflow schematic of the TCV-sGFP coinfiltration assay.

Table 1. Measurements and $P$ values for each viral suppressor of RNA silencing (VSR) when analyzed in the Turnip crinkle virus construct containing a green fluorescent protein reporter gene (TCV-sGFP) complementation and PZP-TCV-sGFP (pPZP212 expressing the TCV CP) coinfiltration assays

\begin{tabular}{|c|c|c|c|c|c|c|}
\hline \multirow[b]{2}{*}{ Construct } & \multicolumn{3}{|c|}{ Complementation assay ${ }^{a}$} & \multicolumn{3}{|c|}{ Coinfiltration assay $^{b}$} \\
\hline & Average diameter $(\mathrm{mm})$ & Standard error & $P$ value $^{\mathrm{c}}$ & Average flux $/ \mathrm{cm}^{2}$ & Standard error & $P$ value $^{\mathrm{c}}$ \\
\hline pPZP212 & 0.434 & 0.013 & 0.500000 & $8.06 \times 10^{9}$ & $4.89 \times 10^{8}$ & 0.500000 \\
\hline TCV CP & 1.041 & 0.045 & $8.24 \times 10^{-15}$ & $1.25 \times 10^{11}$ & $1.89 \times 10^{10}$ & $8.22 \times 10^{-5}$ \\
\hline TBSV p19 & 1.061 & 0.044 & $1.37 \times 10^{-15}$ & $6.25 \times 10^{10}$ & $1.03 \times 10^{10}$ & $2.43 \times 10^{-4}$ \\
\hline TEV HC-Pro & 1.111 & 0.032 & $6.89 \times 10^{-22}$ & $1.12 \times 10^{11}$ & $1.66 \times 10^{10}$ & $7.52 \times 10^{-5}$ \\
\hline FHV B2 & 1.075 & 0.055 & $4.80 \times 10^{-13}$ & $5.11 \times 10^{10}$ & $7.39 \times 10^{9}$ & $1.24 \times 10^{-4}$ \\
\hline VACV E3L & 0.769 & 0.034 & $1.45 \times 10^{-11}$ & $3.03 \times 10^{10}$ & $5.78 \times 10^{9}$ & $1.97 \times 10^{-3}$ \\
\hline FLUAV NS1 & 0.798 & 0.067 & $4.0 \times 10^{-6}$ & $1.35 \times 10^{10}$ & $1.41 \times 10^{9}$ & $1.89 \times 10^{-3}$ \\
\hline CHV-1 p29 & 0.398 & 0.021 & 0.075097 & $9.80 \times 10^{9}$ & $9.96 \times 10^{8}$ & $6.99 \times 10^{-2}$ \\
\hline PVX p25 & 0.486 & 0.041 & 0.117895 & $9.62 \times 10^{9}$ & $1.06 \times 10^{9}$ & 0.10 \\
\hline CMV 2b & 0.807 & 0.039 & $3.96 \times 10^{-11}$ & $2.05 \times 10^{10}$ & $3.25 \times 10^{9}$ & $2.0 \times 10^{-3}$ \\
\hline TGMV AL2 & 0.404 & 0.019 & 0.095639 & $1.31 \times 10^{10}$ & $2.46 \times 10^{9}$ & $3.74 \times 10^{-2}$ \\
\hline
\end{tabular}

${ }^{\text {a }}$ Diameter of 30 foci of infection were measured for each construct, the results averaged, and significance calculated using an unpaired two-sample $t$-test compared with pPZP212.

${ }^{\mathrm{b}}$ A total of 10 leaves were examined for sGFP photon emission per second per $\mathrm{cm}^{2}$ (flux $/ \mathrm{cm}^{2}$ ). Results were averaged and significance was calculated using an unpaired two-sample $t$-test compared with pPZP212.

${ }^{c} P$ values were calculated using an unpaired two-sample $t$-test with pPZP212 as the baseline. Shaded boxes indicate those VSR with a statistically significant increase in either foci diameter or sGFP fluorescence. 
mGC3 resulted in barely detectable fluorescence in the initially inoculated cell with no fluorescence in neighboring cells (data not shown).

\section{TCV CP delivered in trans complements \\ TCV-sGFP movement.}

To determine if providing the $\mathrm{TCV} \mathrm{CP}$ in trans restores TCV-sGFP cell-to-cell movement, $N$. benthamiana was first syringe-infiltrated with Agrobacterium tumefaciens containing the Ti-plasmid-based vector pPZP212 expressing the TCV CP ORF (PZP-TCV CP) (Hajdukiewicz et al. 1994; Qu et al. 2003). After allowing $24 \mathrm{~h}$ for the Agrobacterium infection to establish, TCV-sGFP infectious RNA transcripts were mechanically inoculated onto the same leaves and viewed by fluorescence microscopy 3 dpi (Fig. 2A). Delivery of TCV CP in trans consistently complemented movement of the TCV-sGFP to well beyond the original three to five cells (Fig. 1C, panel c). Measurements of 30 foci of infection showed the average size of TCV-sGFP foci on plants preinfiltrated with the Tiplasmid vector alone (Fig. $1 \mathrm{C}$, panel b) to be $.43 \mathrm{~mm}$ in diameter, while the addition of TCV CP in trans more than doubled the foci size, to an average of over $1.0 \mathrm{~mm}$ (Table 1).

To further elucidate the underlying mechanism of TCVsGFP movement complementation by TCV CP (i.e., direct movement complementation vs. movement indirectly facilitated
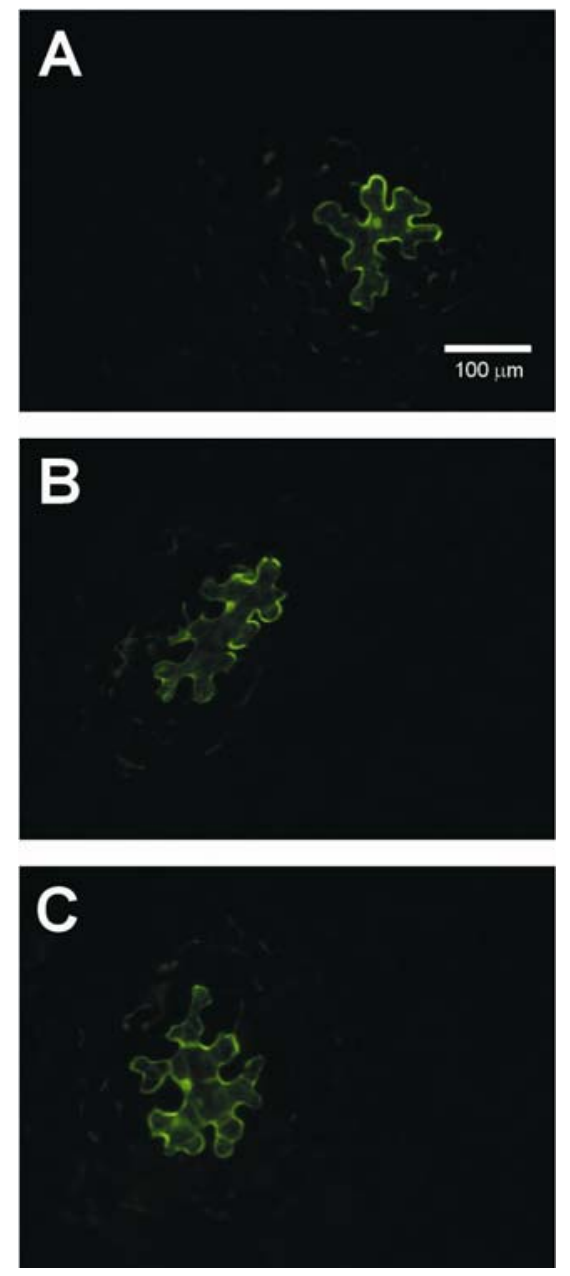

Fig. 3. Turnip crinkle virus coat protein (TCV CP) does not complement movement of the p8/p9 deletion mutant. Images of infection foci 3 days postinoculation on Nicotiana benthamiana. A, TCV $\triangle 92-\mathrm{sGFP}$ with no preinfiltration. B, TCV $\triangle 92-\mathrm{sGFP}$ preinfiltrated with pPZP212. C, TCV $\triangle 92-$-sGP preinfiltrated with PZP-TCV CP. via RNA silencing suppression), a previously characterized 92-nt deletion within the TCV MP ORF (Li et al. 1998) was introduced (construct TCV $\triangle 92$-sGFP; Fig. 1A). This deletion abolishes TCV cell-to-cell movement while still supporting transcription of the subgenomic RNA (sgRNA) expressing sGFP. When infectious transcripts of this construct were mechanically inoculated onto $N$. benthamiana leaves, cell-to-cell movement was completely abolished and only initially infected cells fluoresced (Fig. 3A). An attempt to complement the movement of TCV $492-$ sGFP with PZP-TCV CP failed (Fig. 3C). This confirms that the ability of TCV CP to partially complement TCV-sGFP movement is not due to an intrinsic movement function of the TCV CP, per se.

The TCV CP is the sole structural protein of TCV creating $\mathrm{T}=3$ icosahedral virions (Stockley et al. 1986). While $\mathrm{p} 8$ and p9 are the TCV MP, the CP has also been implicated in facilitating cell-to-cell movement of the virus in certain hosts (Hacker et al. 1992; Li et al. 1998) and this requirement has been assumed to reflect a need for virion formation. To resolve whether the CP is complementing TCV-sGFP movement by virion formation or through suppression of silencing, a TCV $\mathrm{CP}$ mutant, $\mathrm{m} 1$, containing a single amino-acid substitution, was constructed. The $\mathrm{m} 1$ mutation has been previously described as defective for silencing suppression while still allowing for wild-type virion formation in A. thaliana (Deleris et al. 2006). The $\mathrm{m} 1$ site-specific mutation was introduced into pPZP-TCV CP (PZP-TCV CPm1) and was then employed in a standard Agrobacterium coinfiltration assay on N. benthamiana with the GFP reporter that was originally used to identify the TCV CP as a VSR (Qu et al. 2003). While PZP-TCV CP suppressed GFP silencing, PZP-TCV CPm1 did not (Fig. 4A through C). PZP-TCV CPm1 was then examined for its ability to complement TCV-sGFP movement. Infiltration with PZPTCV CPm1 followed by inoculation of TCV-sGFP transcripts failed to advance the infection beyond the initially infected cells, indicating that the complementation with wild-type $\mathrm{CP}$ is a function of its role in silencing suppression and not a direct result of virion formation (Fig. 4D through F).

\section{Heterologous viral suppressors complement TCV-sGFP movement.}

With all evidence pointing to complementation of TCVsGFP movement by its cognate $\mathrm{CP}$ as the result of silencing suppression, we investigated whether this observation could be exploited as an assay to identify other viral suppressors. A spectrum of mechanistically distinct VSR were cloned into the pPZP212 Ti-vector (Fig. 1B) and were tested in what will be subsequently called the TCV-sGFP complementation assay (Fig. 2A). The Ti-vector with a known suppressor insert was mobilized into Agrobacterium tumefaciens and infiltrated onto $N$. benthamiana leaves, followed one day later by mechanical inoculation of TCV-sGFP transcripts. The plant viral suppressors Tobacco etch virus HC-Pro (TEV HC-Pro), Tomato bushy stunt virus p19 (TBSV p19), Potato virus X p25 (PVX p25), Cucumber mosaic virus $2 \mathrm{~b}$ (CMV 2b), and Tomato golden mosaic virus AL2 (TGMV AL2) were each cloned into pPZP212 and assayed. In addition, p29 from the fungus-infecting Cryphonectria hypovirus 1 EP713 (CHV-1 p29), B2 from the insect-infecting Flock house virus (FHV B2), E3L from Vaccinia virus (VACV E3L), and NS1 from Influenza virus (FLUAV NS1) were also assayed. A fluorescence dissecting microscope was used to measure the diameters of 30 infection foci from each suppressor (Fig. 5). The results were averaged, and an unpaired two-sample $t$-test was then performed to calculate the $P$ values for each suppressor as compared with an empty pPZP212 vector. Of the heterologous VSR examined, TEV HC-Pro, TBSV p19, CMV 2b, FHV B2, VACV E3L, and 
FLUAV NS1 all exhibited a statistically significant ability to complement the movement of TCV-sGFP beyond the original three to five cells, while PVX p25, CHV-1 p29, and TGMV AL2 did not complement TCV-sGFP to a statistically significant level (Table 1).

Interestingly, the FHV B2, VACV E3L, and FLUAV NS1 all significantly increased the size of the TCV-sGFP infection foci (Fig. 5A, panels e through g and B; Table 1) with B2 equal to TCV CP in its ability to complement movement. An insectinfecting virus, FHV has been previously reported to infect and replicate inside a variety of plant cells; however, cell-tocell movement in plant tissue does not occur (Dasgupta et al. 2001; Selling et al. 1990). Therefore, it is highly unlikely that FHV B2 possesses any intrinsic plant cell-to-cell movement function. Similarly, VACV and FLUAV are mammalian viruses, and we would once again not expect any plant cell-to-cell movement function from any of their proteins. This further supports the conclusion that the increase in foci size of TCV-sGFP in $N$. benthamiana preinfiltrated with a silencing suppressor is directly correlated with suppressor activity and not a cell-tocell movement function.

\section{Coinfiltration of various suppressors results in silencing suppression.}

Many of the suppressors we observed in the TCV-sGFP complementation assay exhibited clear and unmistakable suppressor activity as measured by the increase in foci size (TBSV p19, TEV HC-Pro, FHV B2). Some, while statistically significant, were not as demonstrable, while still others showed no statistically significant ability to complement TCV-sGFP movement (PVX p25, CHV-1 p29, TGMV AL2). In order to see if this assay could more definitively identify weak and less robust suppressors, a more thorough quantification of TCV-sGFP levels was undertaken. Due to the nature of the complementation assay, the TCV-sGFP infection foci were not large or numerous enough to quantify by Northern blotting or photon emission quantification. To rectify this limitation, the TCV-sGFP construct was cloned into the Ti-plasmid vector pPZP212 (PZPTCV-sGFP) (Fig. 1B). By utilizing Agrobacterium cells to deliver the TCV-sGFP construct, we were able to both infect more cells and more accurately control the amount of TCV-sGFP delivered per leaf. Combining separate cultures of Agrobacterium tumefaciens transformed with PZP-TCV-sGFP and a VSR allowed for whole-leaf examinations. Following a dilution series, we determined that delivery of PZP-TCV-sGFP at a concentration of an optical density at $600 \mathrm{~nm}\left(\mathrm{OD}_{600}\right)=0.0025$ allowed sufficient coverage of the leaf without resulting in an excessive level of background. Similarly, we found that delivery of the suppressor at a concentration $\mathrm{OD}_{600}=0.5$ was sufficient to complement a high percentage of the PZP-TCV-sGFP infection foci and to allow for sGFP quantification.

Agroinfection of TCV-sGFP across an entire leaf allows us to change our focus from small, individual foci of infection to whole-leaf TCV-sGFP expression levels. $N$. benthamiana leaves were coinfiltrated with PZP-TCV-sGFP and each of the PZP-suppressor constructs that were previously examined in the TCV-sGFP complementation assay. Leaves were harvested 5 dpi and were analyzed for evidence of increased TCV-sGFP transcript stability and, thus, silencing suppression (Fig. 2B). Leaves were initially inspected by fluorescence microscopy. Captured images clearly indicated an increase in TCV-sGFP infectivity based on fluorescence of sGFP in coinfiltrations that included TCV CP, TEV HC-Pro, TBSV p19, and FHV B2 (Fig. 6A, panels b through e). Others, such as CMV 2b, VACV E3L, FLUAV NS1, and TGMV AL2 (Fig. 6A, panels f through i) also displayed increased sGFP expression over background levels but not to the same level as the first group.

Next, sGFP fluorescence was quantified to determine which suppressors had a significant effect on PZP-TCV-sGFP infectivity. sGFP fluorescence was measured using the Xenogen IVIS Lumina (IVIS) system (Alameda, CA, U.S.A.), which is capable of detecting sGFP fluorescence in a variety of units, including

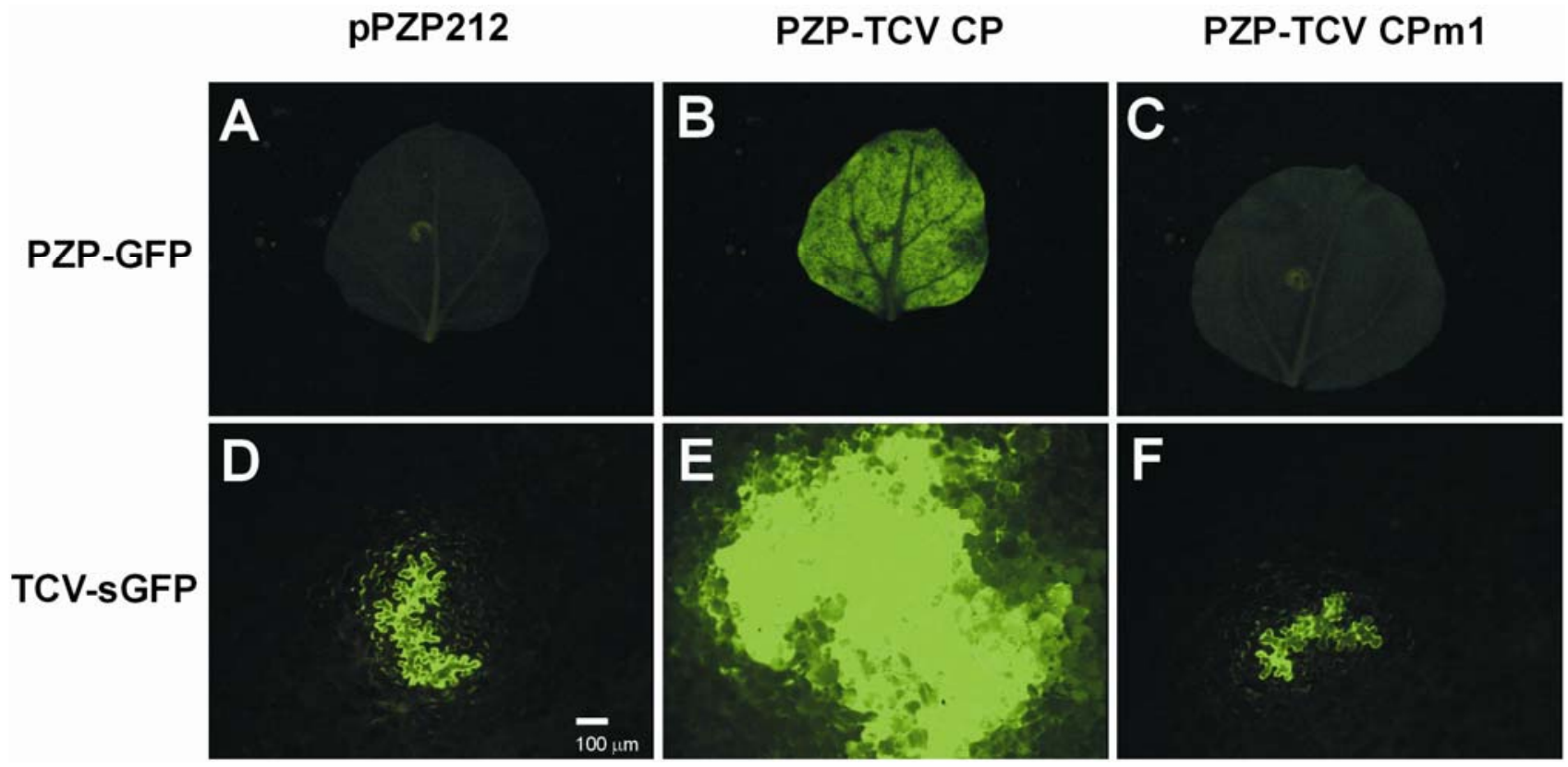

Fig. 4. Complementation of Turnip crinkle virus construct containing a green fluorescent protein reporter gene (TCV-sGFP) movement by TCV coat protein (CP) is not due to virion packaging. The CPm1 mutant contains a point mutation in the TCV CP (G3105A) that has been previously characterized (Deleris et al. 2006) as positive for virion formation but incapable of suppressing RNA silencing in Arabidopsis thaliana. A to C, Agrobacterium coinfiltration assays (5 days postinoculation) and D to $\mathbf{F}$, TCV-sGFP complementation assays (3 days postinoculation), all on Nicotiana benthamiana. A, PZP-GFP with PZP212 vector. B, PZP-GFP with PZP-TCV CP shows suppression of RNA silencing. C, PZP-TCV CPm1 mutant is unable to suppress RNA silencing. D, TCV-sGFP with preinfiltrated PZP212 vector. E, Preinfiltrated PZP-TCV CP complements the movement of TCV-sGFP. F, Preinfiltrated PZP-TCV CPm1 mutant does not complement the movement of TCV-sGFP. 
A
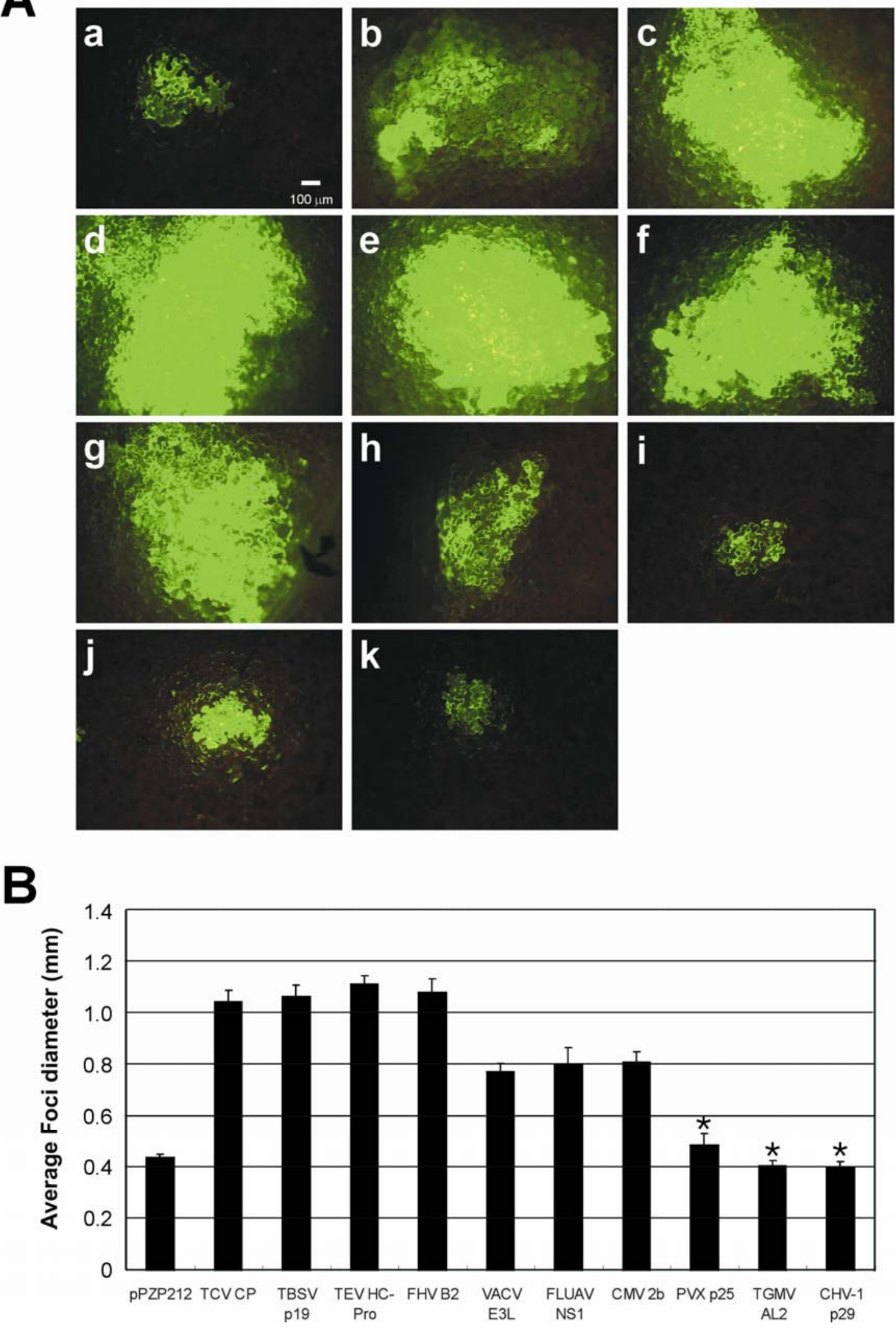

Fig. 5. Turnip crinkle virus construct containing a green fluorescent protein reporter gene (TCV-sGFP) movement can be complemented by a wide range of viral suppressors of RNA silencing (VSR). A, Representative images of TCV-sGFP foci of infection 3 days postinoculation on Nicotiana benthamiana leaves preinfiltrated with the following: a) pPZP212, b) PZP-TCV CP, c) PZP-TBSV p19, d) PZP-TEV HC-Pro, e) PZP-FHV B2, f) PZP-VACV E3L, g) PZPFLUAV NS1, h) PZP-CMV 2b, i) PZP-PVX p25, j) PZP-TGMV AL2, and k) PZP-CHV-1 p29. B, Quantification of TCV-sGFP movement complementation. The diameter of 30 foci of infection were measured 3 days postinoculation for each PZP-VSR construct utilized in the TCV-sGFP complementation assays. An asterisk (*) indicates VSR that do not display a statistically significant difference in foci diameter from the pPZP212 vector. 


\section{A}
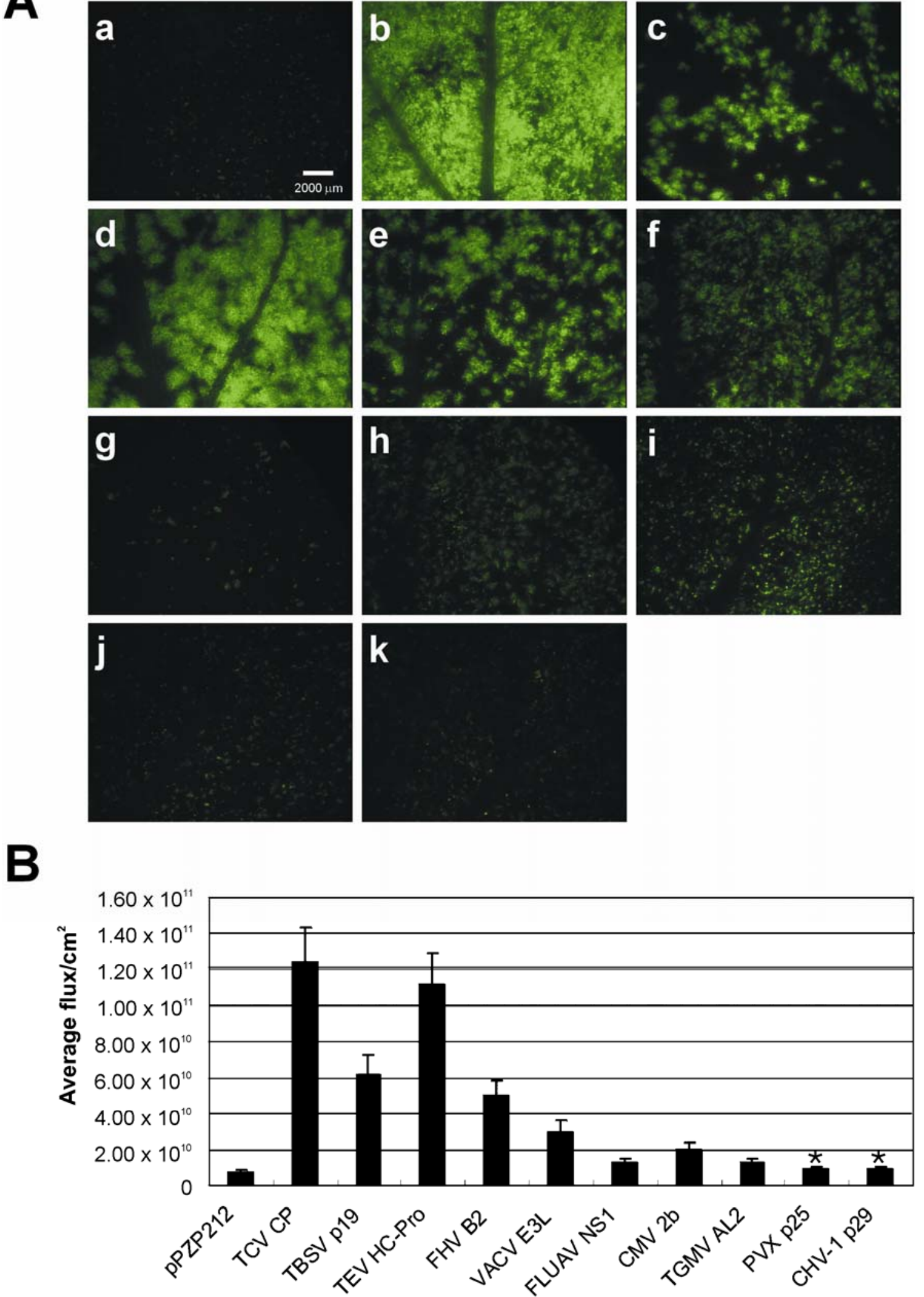

Fig. 6. Ti-plasmid-based vector pPZP212-Turnip crinkle virus construct containing a green fluorescent protein reporter gene (PZP-TCV-sGFP) coinfiltration assay. A, Panels a through k, images of Nicotiana benthamiana leaves 5 days after coinfiltration. Coinfiltration produces a more uniform infection of leaves allowing easier quantification of fluorescence levels. PZP-TCV-sGFP was coinfiltrated with the following: a) pPZP212, b) PZP-TCV CP, c) PZP-TBSV p19, d) PZP-TEV HC-Pro, e) PZP-FHV B2, f) PZP-VACV E3L, g) PZP-FLUAV NS1, h) PZP-CMV 2b, i) PZP-TGMV AL2, j) PZP-PVX p25, and k) PZP-CHV1 p29. B, sGFP fluorescence quantification of PZP-TCV-sGFP coinfiltration assays. Leaves were coinfiltrated with PZP-TCV-sGFP and various PZP-VSR (viral suppressors of RNA silencing) constructs (or control pPZP212) and were analyzed for sGFP fluorescence 5 days postinfiltration. Fluorescence was measured in photons of sGFP emitted per second per square centimeter (flux/cm²). PVX p25 and CHV-1 p29, neither of which showed a statistically significant elevation of sGFP fluorescence are denoted with an asterisk (*). 
photons emitted per second per square centimeter $\left(\mathrm{flux} / \mathrm{cm}^{2}\right)$. Using this system, sGFP fluorescence emitted from each leaf was evaluated, allowing for a quantitative measurement of sGFP fluorescence, a relative indicator of TCV-sGFP replication levels. Ten separate leaves (representing five individual plants) were collected and measured, and standard errors and $P$ values were calculated for each VSR (Table 1; Fig. 6B). Some VSR, such as TCV CP, TEV HC-Pro, TBSV p19, and FHV B2, performed very well in the assay with $P$ values of $\leq 0.001$ when compared with the empty vector (Table 1), while others (VACV E3L, FLUAV NS1, CMV 2b, and TGMV AL2) were found to be significant at the 0.05 significance level after two sample $t$-tests were performed. Two VSR, PVX p 25 and CHV$1 \mathrm{p} 29$, were found to have no increase in sGFP fluorescence as compared with an empty vector (Table 1), as anticipated from their performance in the complementation assay. Interestingly, TGMV AL2, which did not exhibit demonstrable increases in foci size in the TCV-sGFP complementation assay, showed a
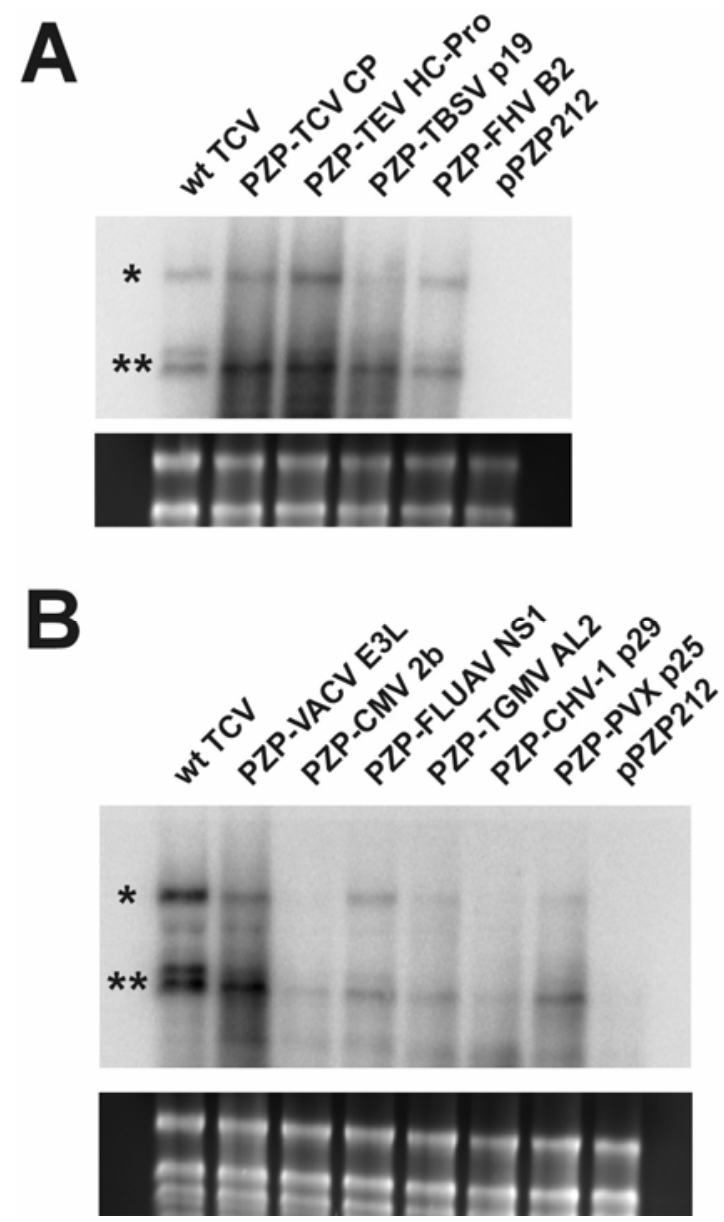

Fig. 7. Northern blot analysis of pPZP212 expressing the Turnip crinkle virus construct containing a green fluorescent protein reporter gene (PZPTCV-sGFP) coinfiltration assays. Total RNA was harvested from leaves coinfiltrated with PZP-TCV-sGFP and various PZP-VSR (viral suppressors of RNA silencing) constructs (or control pPZP212) 5 days postinfiltration. Total RNA $(1 \mu \mathrm{g})$ was loaded into each lane and was probed with a TCV 3 '-specific probe. TCV or TCV-sGFP genomic RNA $(*)$ and subgenomic RNAs $(* *)$ are indicated with asterisks. Lane 1 in both panels is from a wild-type TCV transcript inoculated control. All other lanes are from coinfiltrations with PZP-TCV-sGFP and PZP-VSR, as labeled. A, Northern blot exposed for $24 \mathrm{~h}$. B, Northern blot exposed for $96 \mathrm{~h}$. Some variability from the sGFP fluorescence data was observed but likely reflects sample variability and not a relevant biological phenomenon. For both groups, the upper panel represents the Northern blot, while the lower panel represents the ethidium bromide-stained gel indicating amounts of RNA loaded in each lane. statistically significant increase in sGFP fluorescence in the coinfiltration assay. This is likely due to the point at which AL2 acts in the silencing cascade, as will be discussed later.

Finally, to examine TCV-sGFP RNA accumulation, total RNA was extracted from coinfiltrated leaves and hybridized with a probe specific for the $3^{\prime}$ region of TCV. As expected, those VSR that were found to have $P$ values less than 0.001 in the GFP fluorescence measurements also exhibited an increase in the accumulation and stability of TCV-sGFP genomic RNA, as well as an increase in the stability of the sgRNA that expresses sGFP (Fig. 7A). The other VSR with higher $P$ values did not show this same increase in stability of TCV-sGFP RNAs but were still detectable and noticeably more abundant than when only empty vector was present (Fig. 7B). In general, there was a strong correlation between the Northern analysis and the photon emission results, as those suppressors that had the highest levels of sGFP fluorescence also tended to have the strongest RNA signals.

\section{DISCUSSION}

Utility of the TCV-sGFP assay for new VSR identifications.

Over the past decade viral suppressors of RNA silencing have been broadly grouped into two classes, those that suppress the initiation of RNA silencing and those that reverse preexisting silencing. A variety of assays have been developed to identify these different types of VSR with several becoming widely employed. As with any experimental protocol, there are pros and cons to each assay. One of the easiest and more commonly employed assays is coinfiltration of Agrobacterium tumefaciens containing a Ti-plasmid expressing GFP with that of a Ti-plasmid expressing the protein of interest. A relatively quick and easy method of identifying VSR, it is unable to identify many suppressors due to their mode of action and is not overly sensitive. Other assays that do well at identifying those suppressors that reverse preexisting silencing are insensitive to those VSR that act at the initiation of silencing step. However one thing that all commonly employed VSR assays share is the utilization of a nuclear-localized reporter. This is not surprising, as two of the most ubiquitous genetic manipulations of plants are Agrobacterium infiltration for transient expression and plant transformation for stable transgenic expression. But this might be considered problematic when one considers that the majority of plant viruses are RNA viruses localized to the cytoplasm. While many of the host factors required for the silencing of nuclear-localized transgenes are likely required for the silencing of the cytoplasm-localized virus, adding this extra level of complexity is liable to change some of the factors involved.

Here, we present data supporting a new method for VSR identification that is sensitive, flexible, easy to use, and utilizes a cytoplasm-based reporter. Employing a viral-based assay allows us to more closely mimic natural infection conditions and localization as opposed to the more commonly employed VSR identification procedures. Additionally, the ability of the TCV-sGFP reporter to be used as either an infectious RNA transcript or via agroinfection adds an additional level of flexibility not available with other standard assays. While neither the TCV-sGFP complementation assay nor the PZP-TCV-sGFP coinfiltration assay were positive for all 10 suppressors tested, our assay identified $80 \%$ of the VSR tested, including those from both plant- and animal-infecting viruses, indicating the versatility of the assay. The ability of the TCV-sGFP assay to utilize two delivery methods (cytoplasmic through infectious transcripts and nuclear through agroinfection) was also shown to be noteworthy when the activity of TGMV AL2 was found to be negative in the complementation assay but positive in the 
coinfiltration assay. It appears as though this may be a case in which reporter localization plays a significant role in VSR activity. TGMV is a geminivirus, with a DNA genome localized in the nucleus (Coutts and Buck 1985). The coinfiltration assay for which AL2 was positive relies on TCV-sGFP being initially driven from a nuclear-localized Ti-plasmid. AL2 is thought to primarily affect the silencing cascade by interfering with the endogenous adenosine kinase protein (Wang et al. 2005). Adenosine kinase is involved in the maintenance of the methyl cycle, which, in turn, appears to play a role in DNA methylation and transcriptional gene silencing. This explains why the cytoplasm-based TCV-sGFP complementation assay would be negative for AL2, as infectious TCV-sGFP transcripts are not susceptible to methylation-dependent gene silencing. Indeed a reporter similarly invulnerable to methylation was also unaided by AL2 in an assay that relied on transfection of protoplasts (Qi et al. 2004). Also explained is why AL2 performs relatively weakly in the PZP-TCV-sGFP coinfiltration assay. Methylation-dependent silencing of the PZP-TCV-sGFP presumably plays only a small part in the overall silencing response to TCV-sGFP, with the majority of the RNA silencing response not occurring until the TCV-sGFP starts replicating in the cytoplasm after being initially expressed from the $\mathrm{Ti}$ plasmid. The inability of AL2 activity to be detected when the reporter was wholly cytoplasmic underscores the potential for a DNA virus VSR to be missed by a cytoplasmic-based reporter. While not providing direct evidence for the opposite (an RNA virus VSR undetected by a nuclear-localized reporter), we do believe that this data suggests that the possibility is real.

Other assays make use of disarmed or weakened viruses to provide the silencing inducer, but their target is still generally a nuclear-based reporter. An example of this is the use of Tobacco rattle virus containing a fragment of phytoene desaturase. In the absence of a suppressor, extensive leaf photobleaching can occur, but while the inducer (Tobacco rattle virus expressing phytoene desaturase) is cytoplasm-based, the reporter is still ultimately nuclear-based. The TCV-sGFP complementation assay instead relies on an inducer and reporter that are one and the same, strictly localized in the cytoplasm. There are however some confounding issues when using an actively replicating virus as a reporter. As noted earlier, the assay relies on indirectly evaluating RNA silencing suppression by observation of viral movement via sGFP fluorescence. The underlying basis for these experiments can then be described as the race between the replication and movement of TCVsGFP and the endogenous host-silencing machinery. When the suppressor is absent, the silencing machinery of the plant "catches up" with the replication and movement of TCV by the time the virus spreads to about three to five cells. Of concern is the possibility of an in trans protein extending out the infection foci in a manner independent of RNA silencing suppression. The most obvious example of this would lie with MP from other plant viruses that could potentiate the cell-to-cell movement of TCV. To uncouple movement from potential silencing suppression, we can employ TCV $\Delta 92$-sGFP that is null for movement even when a silencing suppressor is present (Fig. 3). If TCV $\triangle 92$-sGFP movement is not complemented, the candidate VSR has complemented movement of TCVsGFP solely by suppression of RNA silencing. If TCV $\triangle 92-$ sGFP movement can be complemented, the candidate VSR must then be mutated and screened to uncover mutations that uncouple movement from suppression. This approach was employed to elucidate the suppressor activity of the Red clover necrotic mosaic virus MP (J. G. Powers, T. L. Sit, S. H. Park, K. H. Kim, and S. A. Lommel, unpublished data), which had not been previously observed in the Agrobacterium coinfiltration assay (Takeda et al. 2005). Presumably, VSR from viruses that infect nonplant species would not suffer from this pitfall, but prudence suggests that any putative VSR identified in this assay that is thought to have a potential plant cellto-cell movement function should be examined more closely.

Of the ten suppressors examined, two showed no significant silencing suppression in either of the two assays. CHV-1 is a fungi-infecting virus that has been shown to utilize p29 as a VSR (Segers et al. 2006). The apparent lack of CHV-1 p29 suppression in either of the two assays is a bit troubling, as CHV-1 p29 is known to have a degree of amino-acid identity to TEV HC-Pro (Choi et al. 1991; Koonin et al. 1991; Suzuki et al. 1999) that was positive in both assays. Despite this amino-acid identity with HC-Pro, the activity of p29 has been shown to involve blocking the long-distance spread of the silencing signal, and it is this that ultimately accounts for the negative results obtained in this assay (Segers et al. 2006).

The PVX p25 VSR also did not show any signs of silencing suppression in this assay. This is not terribly surprising, as PVX p25 has been previously reported to be incapable of suppressing local silencing of replicating transgenes, specifically a replicating PVX construct delivered by Agrobacterium tumefaciens, and its mode of action is thought to revolve around blocking the spread of the silencing signal itself (Bayne et al. 2005; Voinnet et al. 2000). It is also possible that, as a movement protein, PVX p25 may have a dominant negative effect on the TCV movement proteins $\mathrm{p} 8$ and $\mathrm{p} 9$, thus blocking extensive cell-to-cell movement independently of silencing suppression.

Taken together, the results of CHV-1 p29 and PVX p25 underscore a limitation of the complementation and coinfiltration assay, the inability to identify those suppressors that act to block the spread of the silencing signal. Also explained is the relatively weak results obtained with CMV $2 b$. While $2 b$ is known to directly interact with $\mathrm{AGO}$, it also derives a portion of its antisilencing function from its ability to block the spread of the silencing signal (Brigneti et al. 1998; Zhang et al. 2006). Again, this assay would only examine the former, ignoring the latter and thus resulting in relatively weak results for the $2 \mathrm{~b}$ protein.

\section{A. thaliana vs. $N$. benthamiana RNA silencing.}

Previous reports have shown that TCV can move cell-to-cell in A. thaliana in the absence of a VSR, while cell-to-cell movement in $N$. benthamiana requires a VSR (Cohen et al. 2000; Hacker et al. 1992; Li et al. 1998). To what is this difference attributable? Could it be a simple physical difference at the cellular level that limits the movement of TCV in the absence of a VSR? Or are there inherent differences between the two species of plants in their RNA-silencing responses against invading pathogens? It is this last question that is of particular interest. The widespread conservation of RNA silencing across species is well accepted, but there are well-known differences in the pathway across kingdoms. What of the differences within kingdoms? Certainly some more subtle variability in the RNA silencing pathway exists between families within the plant kingdom. What are they? How large a role do they play in disease susceptibility? The mechanism of RNA silencing against TCV in A. thaliana has been well characterized but not so in $N$. benthamiana (Deleris et al. 2006). The ease with which $A$. thaliana transgenic and knockout plants can be generated, the well-annotated sequence availability, and general ease of use have led to this disparity in knowledge. Use of our TCV-sGFP assays may provide a way to quickly bridge this gap. Transiently silencing components of the silencing pathway in $N$. benthamiana coupled with inoculation of TCV-sGFP infectious transcripts should allow us to identify those components critical for the targeting of RNA viruses by monitoring viral replication and cell-to-cell movement through sGFP fluorescence. Comparisons between these results and 
what has already been published for A. thaliana (Deleris et al. 2006; Himber et al. 2003; Morel et al. 2002) can potentially provide valuable insights into the differences between the RNA silencing cascades of these two species.

The TCV-sGFP system is a versatile and robust reporter assay that can identify and characterize VSR that are not easily recognized by other assays either because of the mode of action or strength of the suppression. This assay is especially valuable in the analysis of potential VSR from RNA viruses, the predominant type of plant virus. Most commonly employed assays utilize nuclear-localized transgenes as reporters, while this assay uses a cytoplasmic-specific reporter, more closely mimicking the conditions found during an RNA virus infection. This system is the latest contribution to the field of RNA silencing in plants and should prove to be invaluable for future studies.

\section{MATERIALS AND METHODS}

\section{Plasmid constructs.}

The Agrobacterium vector pPZP212 has been previously described, as has PZP-TCV CP, PZP-TEV HC-Pro, PZP-TBSV p19, PZP-CMV 2b, TCV T1d1, and pRTL2 (Carrington and Freed 1990; Heaton et al. 1989; Qu et al. 2003).

Construct TCV-mGC3 contains the cycle 3 GFP ORF in place of the CP. Cycle 3 GFP was first mutated to eliminate internal $\mathrm{NcoI}$ and $\mathrm{MscI}$ sites, resulting in $\mathrm{mGC} 3$. Next, an NcoI site was introduced after the fourth amino-acid residue of the $\mathrm{CP}$ followed by fusion of the mGC3 ORF to the residual four amino terminal CP residues (between $\mathrm{NcoI}$ and $\mathrm{MscI}$ ), resulting in construct TCV-mGC3. The mGC3 ORF of TCV-mGC3 was then replaced with the sGFP ORF (Chiu et al. 1996; Sit et al. 1998) by cleavage with $N c o I$ and $M s c I$, followed by ligation to produce TCV-sGFP. TCV-p19 was made similarly, by replacing the mGC3 ORF with the TBSV p19 ORF. TCV $\Delta 92$ p19 was constructed by exchanging the AatII to $\mathrm{Xba \textrm {I }}$ fragment between TCV-p19 and TCV $\Delta 92$ (Li et al. 1998). TCV-sGFP and pTCV $\Delta 92$ p19 were double-digested with $N c o$ I and XbaI, and the fragment released from TCV-sGFP was ligated into pTCV $\Delta 92$ p19 to yield TCV $\triangle 92$-sGFP. PZP-TCV-mGC3 was generated by double-digesting TCV-mGC3 and PZP-TCV $(\mathrm{Qu}$ et al. 2003) with AatII and SpeI. The TCV-mGC3 fragment was subsequently ligated into the PZP-TCV backbone, yielding PZP-TCVmGC3. PZP-TCV-sGFP was constructed by first digesting TCV-mGC3 with $N c o I$ and $M s c I$ and ligating the sGFP ORF to yield the intermediate construct TCVsG6H.1 B/A. TCVsG6H.1 B/A was then digested with AatII and SpeI, and the resultant fragment was ligated into similarly cleaved PZPTCVmGC3 to produce construct PZP-TCV-sGFP.

PZP-TCV CPm1 contains the previously described TCV CP mutant $\mathrm{m} 1$ (Deleris et al. 2006). This point mutation was gen- erated in PZP-TCV CP with the QuikChange II site-directed mutagenesis kit (Stratagene, La Jolla, CA, U.S.A.) and primers TCVCP 364mut(+) and TCVCP 364mut(-). All other PZPVSR constructs were made by cloning of the VSR into pRTL2, followed by subcloning of the entire expression cassette into pPZP212. PZP-FHV B2 was made by amplifying B2 from construct FHV (1, 0) (Ball 1994) with Taq polymerase and primers FHV B2 BspHI(+) and FHV B2 XbaI(-) (Table 2). The resultant polymerase chain reaction fragment was cloned into pGEM-T Easy vector (Promega, Madison, WI, U.S.A.), producing pGEM-B2. pGEM-B2 was double-digested with $B s p \mathrm{HI}$ and $\mathrm{XbaI}$ and ligated into pRTL2 that had been doubledigested with $\mathrm{NcoI}$ and $\mathrm{XbaI}$ to yield construct pRTL2-B2. The B2 insert was then subcloned into pPZP212 via the HindIII site to produce pPZP-FHV B2. PZP-CHV-1 p29 was generated by amplifying p29 from pCPX BSD p29 (Segers et al. 2006) using primers p29 NcoI(+) and p29 XbaI(-) (Table 2). The resultant fragment was double-digested with $\mathrm{NcoI}$ and $\mathrm{XbaI}$ and ligated into pRTL2 to produce pRTL2-p29. The p29 insert was then subcloned into pPZP212 via the HindIII site to yield PZP-CHV-1 p29. PZP-VACV E3L was produced by amplifying E3L from VACV strain Western Reserve DNA (Condit and Motyczka 1981) with primers 5' E3L-Pci and 3' E3L-Xba (Table 2). The resultant fragment was cloned into the pGEM-T Easy vector. pGEM-E3L was subsequently doubledigested with $P c i$ I and $\mathrm{XbaI}$ and ligated into pRTL2 doubledigested with $N c o$ I and $X b a I$ to produce pRTL2-E3L. The E3L insert was then subcloned into pPZP212 via the HindIII site to generate PZP-VACV E3L. PZP-FLUAV NS1 was made by first reverse-transcribing and then amplifying NS1 sequences from Influenza A/PR/8/34 (H1N1) RNA8 with primers 5' NS1-Nco and 3' NS1-Xba (Table 2), prior to cloning into the pGEM-T Easy vector. The internal NcoI site in NS1 was eliminated from the resultant construct, pGEM-NS1, with primers NS1 NcoMut(+) and NS1 NcoMut(-) (Table 2), utilizing the QuikChange II site-directed mutagenesis kit. The mutated pGEM-NS1 insert was cloned into pRTL2 via NcoI and $X b a \mathrm{I}$ sites to produce pRTL2-NS1. The NS1 insert was subcloned into PZP212 via the PstI site to make PZP-FLUAV NS1. PZP-TGMV AL2 was made by amplifying AL2 from pNSB56 with primers AL2 NcoI(+) and AL2 XbaI(-) (Table $2)$. The resultant amplified fragment was double-digested with NcoI and XbaI and ligated into pRTL2 to produce pRTL2AL2. The AL2 insert was then subcloned into PZP212 via the HindIII site to generate PZP-TGMV AL2.

\section{Preparation of Agrobacterium cultures for infiltration.}

Agrobacterium cultures were prepared for infiltration by previously described methods (Llave et al. 2000). Briefly, individual colonies were inoculated into 2-ml Luria-Bertani (LB)

Table 2. Oligonucleotides used in cloning and site-directed mutagenesis

\begin{tabular}{|c|c|c|}
\hline Name & Sequence & Restriction Site added \\
\hline TCVCP 364mut(+) & CCAGCTCATTAAGAAGGCGGCCCAGTATG & None \\
\hline TCVCP 364mut(-) & CATACTGGGCCGCCTTCTTAATGAGCTGG & None \\
\hline FHV B2 BspHI(+) & CGCTCATGATGCCAAGCAAACTCGCGCTAATCC & BspHI \\
\hline FHV B2 XbaI(-) & GTCTAGACTACAGTTTTGCGGGTGGGGGGT & $X b a \mathrm{I}$ \\
\hline p29 NcoI(+) & GGCCCATGGCTCAATTAAGAAAACCCAGTC & NcoI \\
\hline p29 XbaI (-) & GGCTCTAGACTAGCCAATCCGGGCAAGGGGATCC & $X b a \mathrm{I}$ \\
\hline 5' E3L-Pci & TACATGTCTAAAATCTATATCGACGAGCGTTC & PciI \\
\hline 3' E3L-Xba & TTCTAGAATCAGAATCTAATGATGACGTAACCAAG & $X b a \mathrm{I}$ \\
\hline $5^{\prime} \mathrm{NS} 1-\mathrm{Nco}$ & TCCATGGATCCAAACACTGTGTCAAGCTTTCAGG & NcoI \\
\hline 3' NS1-Xba & TTCTAGATTAAACTTCTGACCTAATTGTTCCCGCC & $X b a \mathrm{I}$ \\
\hline NS1 NcoMut(+) & GGCACTTAAAATGACTATGGCCTCTGTACC & None \\
\hline NS1 NcoMut(-) & GGTACAGAGGCCATAGTCATTTTAAGTGCC & None \\
\hline $\mathrm{AL} 2 \mathrm{NcoI}(+)$ & CCGCCATGGGGATGCGAAATTCGTCTTCCTCA & NcoI \\
\hline AL2 XbaI(-) & GGCTCTAGACTATTTAAATAAGTTCTCCCAGAAGC & $X b a \mathrm{I}$ \\
\hline
\end{tabular}


broth cultures with the appropriate antibiotics and were incubated at $28^{\circ} \mathrm{C}$ for $20 \mathrm{~h}$ with shaking. From these initial cultures, $250 \mu \mathrm{l}$ was used to inoculate $5-\mathrm{ml}$ LB broth cultures with the appropriate antibiotics and $40 \mu \mathrm{M}$ acetosyringone and $10 \mathrm{mM}$ morpholineethanesulfonic acid (MES), pH 5.6. These cultures were similarly incubated at $28^{\circ} \mathrm{C}$ for $20 \mathrm{~h}$ with shaking. Cultures were subsequently pelleted, resuspended in 10 $\mathrm{mM} \mathrm{MgCl} 2,10 \mathrm{mM} \mathrm{MES}, \mathrm{pH}$ 5.6, and $200 \mu \mathrm{M}$ acetosyringone to the appropriate $\mathrm{OD}_{600}$ reading and were incubated at room temperature for at least $3 \mathrm{~h}$ prior to syringe infiltration into plants.

\section{TCV-sGFP complementation assay.}

The TCV-sGFP complementation assay is illustrated schematically in Figure 2A. Two $N$. benthamiana leaves per plant were first infiltrated from the abaxial side with Agrobacterium cultures containing various PZP-VSR constructs or controls at an $\mathrm{OD}_{600}=1$. At $24 \mathrm{~h}$ postinfiltration, TCV-sGFP infectious RNA transcripts were mechanically inoculated onto the Carborundum-dusted abaxial surfaces of these same infiltrated leaves. The infection process was evaluated 3 days after transcript inoculation, with a Leica MZIII fluorescence dissecting microscope equipped with a GFP filter. Each assay was repeated at least four times.

\section{PZP-TCV-sGFP coinfiltration assay.}

The PZP-TCV-sGFP coinfiltration assay is illustrated schematically in Figure 2B. Agrobacterium cultures containing the various PZP-VSR constructs or controls (final $\mathrm{OD}_{600}=0.5$ ) were mixed with an Agrobacterium culture containing PZPTCV-sGFP (final $\mathrm{OD}_{600}=0.0025$ ) and were syringe-infiltrated into the abaxial side of two $N$. benthamiana leaves per plant. Leaves were evaluated 5 days after infiltration, with the fluorescence dissecting microscope, and fluorescence levels were quantified with the IVIS system. Each assay was repeated at least five times.

\section{IVIS system.}

The IVIS Lumina system (Xenogen Corp.) is capable of quantifying photon emission from a variety of sources. A CCD camera measured and recorded photon emission data, which was then incorporated into Living Image Software Version 2.6 (Xenogen Corp.) for further analysis. Whole leaves were placed under the CCD camera and measurements were taken with a subject height of $0.5 \mathrm{~cm}$, GFP excitation filter, and exposure time of $1 \mathrm{~s}$. After fluorescence readings were taken they were exported to Microsoft Excel for further statistical analysis.

\section{RNA extraction and Northern analysis.}

Total RNAs were extracted from coinfiltrated leaves with the RNeasy plant mini kit (Qiagen, Valencia, CA, U.S.A.) according to the manufacturer's instructions. Total RNA concentrations were measured with a ND-1000 spectrophotometer (Nanodrop, Wilmington, DE, U.S.A.), and $1 \mu \mathrm{g}$ of each sample was electrophoresed through a $1 \%$ agarose gel, transferred to nylon membranes, and hybridized with a ${ }^{32} \mathrm{P}-\mathrm{dCTP}-\mathrm{labeled}$ probe specific for the $3^{\prime}$ end of TCV. Probe was generated by digesting TCV 3d1 with $M s c I$ and $X b a I$, releasing a fragment from base pair 3,384 to the $3^{\prime}$ end. Hybridized blots were exposed to Kodak K-screens for 24 and 96 h (Groups 1 and 2, respectively).

\section{ACKNOWLEDGMENTS}

We thank R. Dasgupta for FHV $(1,0)$ from which B2 was amplified, D. Nuss for providing pCPX BSD p29, from which we amplified CHV-1 p29, T. Petty for Influenza virus A/PR/8/34 (H1N1) RNA and Vaccinia virus
Western Reserve strain DNA, and L. Hanley-Bowdoin for plasmid pNSB56, from which TGMV AL2 was amplified. We thank N. Allen and E. Johannes at the Cellular and Molecular Imaging Facility, North Carolina State University (NCSU) for assistance with the Leica fluorescence dissecting microscope, G. Dean and A. LaVoy for training and use of the IVIS Lumina System at the NCSU College of Veterinary Medicine, and D. Robertson for valuable comments and insight. Statistical analysis assistance was provided by D. Schumann of the NCSU Statistics Department. J. G. Powers was supported by a National Institutes of Health-NCSU Molecular Biotechnology traineeship. This research was supported in part by National Science Foundation grants MCB-0077964 and MCB-0651263 to S. A. Lommel and T. L. Sit.

\section{LITERATURE CITED}

Anandalakshmi, R., Pruss, G. J., Ge, X., Marathe, R., Mallory, A. C., Smith, T. H., and Vance, V. B. 1998. A viral suppressor of gene silencing in plants. Proc. Natl. Acad. Sci. U.S.A. 95(22):13079-13084.

Ball, L. A. 1994. Replication of the genomic RNA of a positive-strand RNA animal virus from negative-sense transcripts. Proc. Natl. Acad. Sci. U.S.A. 91:12443-12447.

Baumberger, N., and Baulcombe, D. C. 2005. Arabidopsis ARGONAUTE1 is an RNA slicer that selectively recruits microRNAs and short interfering RNAs. Proc. Natl. Acad. Sci. U.S.A. 102:11928-11933.

Bayne, E. H., Rakitina, D. V., Morozov, S. Y., and Baulcombe, D. C. 2005. Cell-to-cell movement of potato potexvirus $\mathrm{X}$ is dependent on suppression of RNA silencing. Plant J. 44:471-482.

Bernstein, E., Caudy, A. A., Hammond, S. M., and Hannon, G. J. 2001. Role for a bidentate ribonuclease in the initiation step of RNA interference. Nature 409:363-366.

Blevins, T., Rajeswaran, R., Shivaprasad, P.V., Beknazariants, D., SiAmmour, A., Park, H. S., Vazquez, F., Robertson, D., Meins, F., Jr., Hohn, T., and Pooggin, M. M. 2006. Four plant Dicers mediate viral small RNA biogenesis and DNA virus induced silencing. Nucleic Acids Res. 34:6233-6246.

Brigneti, G., Voinnet, O., Li, W. X., Ji, L. H., Ding, S. W., and Baulcombe, D. C. 1998. Viral pathogenicity determinants are suppressors of transgene silencing in Nicotiana benthamiana. EMBO (Eur. Mol. Biol. Organ.) J. 17:6739-6746

Carrington, J. C., and Freed, D. D. 1990. Cap-independent enhancement of translation by a plant potyvirus $5^{\prime}$ nontranslated region. J. Virol. 64:1590-1597.

Chapman, E. J., and Carrington, J. C. 2007. Specialization and evolution of endogenous small RNA pathways. Nat. Rev. Genet. 8:884-896.

Chiu, W., Niwa, Y., Zeng, W., Hirano, T., Kobayashi, H., and Sheen, J. 1996. Engineered GFP as a vital reporter in plants. Curr. Biol. 6:325330.

Choi, G. H., Shapira, R., and Nuss, D. L. 1991. Cotranslational autoproteolysis involved in gene expression from a double-stranded RNA genetic element associated with hypovirulence of the chestnut blight fungus. Proc. Natl. Acad. Sci. U.S.A. 88:1167-1171.

Cohen, Y., Gisel, A., and Zambryski, P. C. 2000. Cell-to-cell and systemic movement of recombinant green fluorescent protein-tagged turnip crinkle viruses. Virology 273:258-266.

Condit, R. C., and Motyczka, A. 1981. Isolation and preliminary characterization of temperature-sensitive mutants of vaccinia virus. Virology 113:224-241.

Coutts, R. H., and Buck, K. W. 1985. DNA and RNA polymerase activities of nuclei and hypotonic extracts of nuclei isolated from tomato golden mosaic virus infected tobacco leaves. Nucleic Acids Res. 13:78817897.

Dasgupta, R., Garcia, B. H., 2nd and Goodman, R. M. 2001. Systemic spread of an RNA insect virus in plants expressing plant viral movement protein genes. Proc. Natl. Acad. Sci. U.S.A. 98:4910-4915.

Deleris, A., Gallego-Bartolome, J., Bao, J., Kasschau, K. D., Carrington, J. C., and Voinnet, O. 2006. Hierarchical action and inhibition of plant Dicer-like proteins in antiviral defense. Science 313:68-71.

Galiana-Arnoux, D., Dostert, C., Schneemann, A., Hoffmann, J. A., and Imler, J. L. 2006. Essential function in vivo for Dicer-2 in host defense against RNA viruses in drosophila. Nat. Immunol. 7:590-597.

Hacker, D. L., Petty, I. T., Wei, N., and Morris, T. J. 1992. Turnip crinkle virus genes required for RNA replication and virus movement. Virology 186:1-8.

Hajdukiewicz, P., Svab, Z., and Maliga, P. 1994. The small, versatile pPZP family of Agrobacterium binary vectors for plant transformation. Plant Mol. Biol. 25:989-994.

Heaton, L. A., Carrington, J. C., and Morris, T. J. 1989. Turnip crinkle virus infection from RNA synthesized in vitro. Virology 170:214-218.

Himber, C., Dunoyer, P., Moissiard, G., Ritzenthaler, C., and Voinnet, O. 
2003. Transitivity-dependent and -independent cell-to-cell movement of RNA silencing. EMBO (Eur. Mol. Biol. Organ.) J. 22:4523-4533.

Johansen, L. K., and Carrington, J. C. 2001. Silencing on the spot. Induction and suppression of RNA silencing in the Agrobacterium-mediated transient expression system. Plant Physiol. 126:930-938.

Kasschau, K. D., and Carrington, J. C. 1998. A counterdefensive strategy of plant viruses: Suppression of posttranscriptional gene silencing. Cell 95:461-470.

Koonin, E. V., Choi, G. H., Nuss, D. L., Shapira, R., and Carrington, J. C. 1991. Evidence for common ancestry of a chestnut blight hypovirulence-associated double-stranded RNA and a group of positive-strand RNA plant viruses. Proc. Natl. Acad. Sci. U.S.A. 88:10647-10651.

Li, F., and Ding, S. W. 2006. Virus counterdefense: Diverse strategies for evading the RNA-silencing immunity. Annu. Rev. Microbiol. 60:503531.

Li, H., Li, W. X., and Ding, S. W. 2002. Induction and suppression of RNA silencing by an animal virus. Science 296:1319-1321.

Li, W. X., Li, H., Lu, R., Li, F., Dus, M., Atkinson, P., Brydon, E. W., Johnson, K. L., Garcia-Sastre, A., Ball, L. A., Palese, P., and Ding, S. W. 2004. Interferon antagonist proteins of influenza and vaccinia viruses are suppressors of RNA silencing. Proc. Natl. Acad. Sci. U.S.A. 101:1350-1355

Li, W. Z., Qu, F., and Morris, T. J. 1998. Cell-to-cell movement of turnip crinkle virus is controlled by two small open reading frames that function in trans. Virology 244:405-416.

Llave, C., Kasschau, K. D., and Carrington, J. C. 2000. Virus-encoded suppressor of posttranscriptional gene silencing targets a maintenance step in the silencing pathway. Proc. Natl. Acad. Sci. U.S.A. 97:13401-13406.

Lu, R., Folimonov, A., Shintaku, M., Li, W. X., Falk, B. W., Dawson, W. O., and Ding, S. W. 2004. Three distinct suppressors of RNA silencing encoded by a $20-\mathrm{kb}$ viral RNA genome. Proc. Natl. Acad. Sci. U.S.A. 101:15742-15747.

Morel, J. B., Godon, C., Mourrain, P., Beclin, C., Boutet, S., Feuerbach, F., Proux, F., and Vaucheret, H. 2002. Fertile hypomorphic ARGONAUTE (ago1) mutants impaired in post-transcriptional gene silencing and virus resistance. Plant Cell 14:629-639.

Mourrain, P., Beclin, C., Elmayan, T., Feuerbach, F., Godon, C., Morel, J B., Jouette, D., Lacombe, A. M., Nikic, S., Picault, N., Remoue, K., Sanial, M., Vo, T. A., and Vaucheret, H. 2000. Arabidopsis SGS2 and SGS3 genes are required for posttranscriptional gene silencing and natural virus resistance. Cell 101:533-542.

Napoli, C., Lemieux, C., and Jorgensen, R. 1990. Introduction of a chimeric chalcone synthase gene into petunia results in reversible co-suppression of homologous genes in trans. Plant Cell 2:279-289.

Qi, Y., Zhong, X., Itaya, A., and Ding, B. 2004. Dissecting RNA silencing in protoplasts uncovers novel effects of viral suppressors on the silencing pathway at the cellular level. Nucleic Acids Res. 32(22):e179. Published online.

Qu, F., and Morris, T. J. 2005. Suppressors of RNA silencing encoded by plant viruses and their role in viral infections. FEBS (Fed. Eur. Biochem. Soc.) Lett. 579:5958-5964.

Qu, F., Ren, T., and Morris, T. J. 2003. The coat protein of turnip crinkle virus suppresses posttranscriptional gene silencing at an early initiation step. J. Virol. 77:511-522.

Ren, T., Qu, F., and Morris, T. J. 2000. HRT gene function requires interaction between a NAC protein and viral capsid protein to confer resistance to turnip crinkle virus. Plant Cell 12:1917-1926.

Ren, T., Qu, F., and Morris, T. J. 2005. The nuclear localization of the Arabidopsis transcription factor TIP is blocked by its interaction with the coat protein of Turnip crinkle virus. Virology 331:316-324.

Segers, G. C., van Wezel, R., Zhang, X., Hong, Y., and Nuss, D. L. 2006. Hypovirus papain-like protease p29 suppresses RNA silencing in the natural fungal host and in a heterologous plant system. Eukaryot. Cell 5:896-904.

Selling, B. H., Allison, R. F., and Kaesberg, P. 1990. Genomic RNA of an insect virus directs synthesis of infectious virions in plants. Proc. Natl. Acad. Sci. U.S.A. 87:434-438.

Sit, T. L., Vaewhongs, A. A., and Lommel, S. A. 1998. RNA-mediated trans-activation of transcription from a viral RNA. Science 281:829. 832.

Song, J. J., Smith, S. K., Hannon, G. J., and Joshua-Tor, L. 2004. Crystal structure of Argonaute and its implications for RISC slicer activity. Science 305:1434-1437.

Stockley, P. A., Kirsh, A. L., Chow, E. P., Smart, J. E., and Harrison, S. C. 1986. Structure of Turnip crinkle virus. III. Identification of a unique coat protein dimer. J. Mol. Biol. 191:721-725.

Suzuki, N., Chen, B., and Nuss, D. L. 1990. Mapping of a hypovirus p29 protease symptom determinant domain with sequence similarity to potyvirus HC-Pro protease. J. Virol. 73:9478-9484.

Tabara, H., Sarkissian, M., Kelly, W. G., Fleenor, J., Grishok, A Timmons, L., Fire, A., and Mello, C. C. 1990. The rde-1 gene, RNA interference, and transposon silencing in C. elegans. Cell 99:123-132.

Takeda, A., Tsukuda, M., Mizumoto, H., Okamoto, K., Kaido, M., Mise, K., and Okuno, T. 2005. A plant RNA virus suppresses RNA silencing through viral RNA replication. EMBO (Eur. Mol. Biol. Organ.) J. 24:3147-3157.

Voinnet, O. 2001. RNA silencing as a plant immune system against viruses. Trends Genet. 17:449-459.

Voinnet, O., Lederer, C., and Baulcombe, D. C. 2000. A viral movement protein prevents spread of the gene silencing signal in Nicotiana benthamiana. Cell 103:157-167.

Volpe, T. A., Kidner, C., Hall, I. M., Teng, G., Grewal, S. I., and Martienssen, R. A. 2002. Regulation of heterochromatic silencing and histone H3 lysine-9 methylation by RNAi. Science 297:1833-1837.

Wang, H., Buckley, K. J., Yang, X., Buchmann, R. C., and Bisaro, D. M. 2005. Adenosine kinase inhibition and suppression of RNA silencing by geminivirus AL2 and L2 proteins. J. Virol. 79:7410-7418.

Wang, X. H., Aliyari, R., Li, W. X., Li, H. W., Kim, K., Carthew, R., Atkinson, P., and Ding, S. W. 2006. RNA interference directs innate immunity against viruses in adult Drosophila. Science 312:452-454.

Zhang, X., Yuan, Y. R., Pei, Y., Lin, S. S., Tuschl, T., Patel, D. J., and Chua, N. H. 2006. Cucumber mosaic virus-encoded 2b suppressor inhibits Arabidopsis Argonaute1 cleavage activity to counter plant defense. Genes Dev. 20:3255-3268. 